\title{
Health System Preparedness for Coincidence of Natural Disasters and COVID-19: A Systematic Literature Review
}

Sanaz Sohrabizadeh ( $\sim$ ssohrabizadeh@gmail.com )

Shahid Beheshti University of Medical Sciences

Shiva Yousefian

Shahid Beheshti University of Medical Sciences

Amir hosein Bahramzadeh

Shahid Beheshti University of Medical Sciences

Mohammad Hosein Vaziri

Shahid Beheshti University of Medical Sciences

\section{Research Article}

Keywords: COVID-19 pandemic, Natural disasters, Earthquakes, Coincidence

Posted Date: January 5th, 2021

DOI: https://doi.org/10.21203/rs.3.rs-118316/v1

License: (a) (i) This work is licensed under a Creative Commons Attribution 4.0 International License.

Read Full License

Version of Record: A version of this preprint was published at BMC Public Health on April 13th, 2021. See the published version at https://doi.org/10.1186/s12889-021-10806-9. 


\section{Abstract}

Background: In December 2019, the Chinese city of Wuhan has reported a novel pneumonia caused by COVID-19. While the COVID-19 pandemic has been increasingly affecting the world, the occurrence of natural disasters resulted in complex emergencies. The present review is aimed to identify the research focused on coincidence of natural disasters and COVID-19 and describe the preparedness and response actions applied by affected countries.

Methods: This study was conducted and reported based on PRISMA checklist. The databases of Web of Sciences, PubMed, Scopus, Google Scholar and World Health Organization Library were searched. The inclusion criteria were all forms of published articles which investigated the dual risk or coincidence of natural disasters and COVID-19 pandemic. Once the studies selection was completed and the relevant papers was finalized, the analysis was done.

Findings: Out of 1245 studies generated by initial search, a number of 13 articles was selected for final analysis. Earthquake was the most frequent disaster which its coincidence with COVID-19 was studied by researchers (31\%). The implications of researchers for healthcare system were explained in three sections of climatic events, earthquakes and all hazard approach in relation to COVID-19.

Conclusion: Extracting the lessons learned from the regions affected by disasters at the time of COVID-19 pandemic can be helpful for healthcare professionals and policy-makers to modify their preparedness and response plans for cascading risk of natural disasters and a serious pandemic such as COVID-19. Further research is needed to identify the factors strengthen the preparedness of health system for the dual risk of natural hazards and pandemics.

\section{Background}

Natural disasters are catastrophic events with serious health, social, and economic consequences. Natural disasters have killed millions of people, adversely affected the lives of about 1 billion populations, and resulted in remarkable socio-economic consequences during the last two decades. Developing countries are disproportionately affected due to the insufficient resources, unsafe infrastructure, and lack of disaster preparedness systems (1). Global population growth, poverty, and the urbanization in many countries have increased the number of people living in highly disaster-prone regions and multiplied their public health effects (2). On the other hand, natural disasters always cause several health effects such as injuries, pandemics and sanitation. There is an imbalance between requests for healthcare services and the capacity of healthcare services to respond at the time of disasters. Furthermore, the response might be weekend due to destructed health care facilities, loss of medical equipment and logistics as well as healthcare personnel's deaths and injuries (3).

In December 2019, the Chinese city of Wuhan has reported a novel pneumonia caused by coronavirus disease (COVID-19), which has been spreading internationally. Coronavirus is one of the major pathogens that primarily target the human respiratory system. Previous outbreaks of coronaviruses (CoVs) included 
the severe acute respiratory syndrome (SARS)-CoV and the Middle East respiratory syndrome (MERS)$\mathrm{CoV}$ which have been previously characterized as an agent of great public health threat $(4,5)$. While the COVID-19 pandemic has been increasingly affecting the world, the occurrence of natural disasters such as earthquakes, floods and tornadoes in several countries resulted in complex emergencies. For instance, a number of 15 earthquakes in China at the time of COVID-19 epidemic aggravated the fears and anxiety of Chinese people. In addition, flash floods, bushfires, and dust storms of Australia, killed at least 33 people and more than a billion animals, and destroyed thousands of homes in 2020 (6). In America, since the start of the COVID-19 pandemic, several natural disasters have occurred including dozens of tornados in southern states; earthquake in Nevada with damaging to the main highway; tropical storm Cristobal in Florida; flash-floods in Wisconsin; and Hurricane Hanna in Texas Gulf Coast (7). Flash floods occurred in the southern provinces of Iran resulted in some deaths and considerable destructions in during COVID-19 earthquake on March 2020. The coincidence of COVID-19 and Tehran earthquake in May 2020 resulted in serious stress, anxiety and panic reactions which caused injuries and damages $(8,9)$. Thus, coincidence of COVID-19 and natural disasters can intensify destructions and public health consequences.

Natural disaster can impose multiple pressure on the health systems and cause disruptions for providing health services $(7,10)$. Furthermore, disasters-affected people live in temporary overcrowded shelters with inadequate health facilities and insufficient ventilation. Such conditions can exacerbate the Covid-19 pandemic due to the increase the increase of communicable diseases which are transmitted by water, air and vectors (11). Accordingly, COVID-19 pandemic can significantly affect the disaster exposure and vulnerability as well as capacities of health systems $(12,13)$.

A number of studies reported the relationship between natural disasters and communicable diseases. Many authors implied that the risk of communicable diseases have increased during and after natural disasters. For instance, several researches declared that post-disaster changes such as stress, hygiene, and environmental issues have caused various infectious diseases in disaster-stricken regions (14-16). The effects of coincidence of natural disasters and COVID-19 pandemic on the community health highlight an urgent need for merging disaster risk reduction strategies into courtiers" response plans (10, 17, 18). A few publications have studied the coincidence of natural disasters and COVID-19 pandemic and its effects on health system preparedness and response. Therefore, the present systematic review is

aimed to identify the research focused on coincidence of natural disasters and COVID-19 and describe the preparedness and response actions applied by affected countries.

\section{Methods}

Databases and Search Strategy

The databases of Web of Sciences, PubMed, Scopus, Google Scholar and World Health Organization Library were searched using related keywords selected through PubMed MeSH terms, similar articles and documents as well as experts suggestions. Reference lists of relevant articles and systematic reviews were searched as well. The main search term included COVID-19, natural disasters, health, health system, 
preparedness, and disaster management. The strategy of search was made by using AND/OR between selected terms and keywords. In order to increasing the probability of identification of all relevant literature, the keywords were finalized based on the agreement among three researchers. The search terms were used in titles, abstracts, text, and keywords of articles. The literature search was conducted in September 2020.

\section{Inclusion and exclusion criteria}

The research team applied inclusion and exclusion criteria for selecting relevant studies. The inclusion criteria were determined as all forms of published articles (e.g. original paper, letter to editor, case study and commentary) which investigated the dual risk or coincidence of natural disasters and COVID-19 pandemic in the world. The exclusion criteria included documents were not published in English, and online news and reports as well as articles which their abstracts could not be accessed.

\section{Studies selection and analysis process}

Using the title and abstract screening, and given the inclusion criteria, the selection of studies were performed by two researchers. In the next step, the full text of the remaining articles was analyzed independently by the two researchers considering the inclusion and exclusion criteria. The discrepancies were discussed and in cases without any agreement, a third person was the final decision maker to include the documents. The studies that met one of the exclusion criteria were rejected.

Once the studies selection was completed and the relevant papers was finalized, primary analysis was done to clarify the main characteristics of the selected literature. Accordingly, for all documents, authors were developed a checklist based on four main sections of setting, study design, findings and implication for health system. Then, the data extraction sheet was designed by each study's information such as title, name(s) of the author(s), publication year, data source, journal's name and article type. All extracted data was evaluated by members of the research team to verify accuracy and completeness. In order to manage the citations, EndNote software, version 17, was used, and all duplicated records were excluded. The present systematic review was conducted and reported based on PRISMA checklist (Figure 1).

\section{Findings}

A number of 1245 studies was generated by initial search. After removing the duplication, 555 references were identified for screening. Out of 555 extracted studies, 530 articles were removed due to meeting the exclusion criteria. The full texts of 25 studies were read and 13 articles which included the co-occurrence of natural disasters and COVID-19 as well as implications for health system were selected for final analysis (Figure 1) (Table 1). 
Table 1) The characteristics of the final selected articles 


\begin{tabular}{|c|c|c|c|c|c|}
\hline No & Title & $\begin{array}{l}\text { Publication } \\
\text { month }\end{array}$ & $\begin{array}{l}\text { Article } \\
\text { type }\end{array}$ & Disaster type & Health effects \\
\hline \multirow[t]{2}{*}{1} & \multirow[t]{2}{*}{$\begin{array}{l}\text { The COVID-19 Pandemic and } \\
\text { Wildfire Smoke: Potentially } \\
\text { Concomitant Disasters }\end{array}$} & \multirow[t]{2}{*}{$\begin{array}{l}\text { August } \\
2020\end{array}$} & \multirow[t]{2}{*}{ Editorial } & \multirow[t]{2}{*}{ Wildfire } & $\begin{array}{l}\text { Physical } \\
\text { health; }\end{array}$ \\
\hline & & & & & $\begin{array}{l}\text { Environmental } \\
\text { health }\end{array}$ \\
\hline 2 & $\begin{array}{l}\text { Stay home while going out - } \\
\text { Possible impacts of } \\
\text { earthquake co-occurring with } \\
\text { COVID- } 19 \text { pandemic on } \\
\text { mental health and vice versa }\end{array}$ & April 2020 & Editorial & Earthquake & Mental health \\
\hline 3 & $\begin{array}{l}\text { Mitigating the Twin Threats } \\
\text { of Climate-Driven Atlantic } \\
\text { Hurricanes and COVID-19 } \\
\text { Transmission }\end{array}$ & July 2020 & $\begin{array}{l}\text { Policy } \\
\text { analysis }\end{array}$ & Hurricane & $\begin{array}{l}\text { Healthcare } \\
\text { system }\end{array}$ \\
\hline 4 & $\begin{array}{l}\text { Living in a Multi-Risk Chaotic } \\
\text { Condition: Pandemic, Natural } \\
\text { Hazards and Complex } \\
\text { Emergencies }\end{array}$ & $\begin{array}{l}\text { August } \\
2020\end{array}$ & $\begin{array}{l}\text { Original } \\
\text { research }\end{array}$ & Flood/earthquake & $\begin{array}{l}\text { Healthcare } \\
\text { system }\end{array}$ \\
\hline 5 & $\begin{array}{l}\text { From natural disaster to } \\
\text { pandemic: A health system } \\
\text { pharmacy rises to the } \\
\text { challenge }\end{array}$ & May 2020 & $\begin{array}{l}\text { Case } \\
\text { report }\end{array}$ & Tornado & $\begin{array}{l}\text { Health system } \\
\text { pharmacy }\end{array}$ \\
\hline 6 & $\begin{array}{l}\text { Floods in China, COVID-19, } \\
\text { and climate change }\end{array}$ & $\begin{array}{l}\text { August } \\
2020\end{array}$ & Editorial & Flood & Health system \\
\hline 7 & $\begin{array}{l}\text { Earthquake in the time of } \\
\text { COVID-19: The story from } \\
\text { Croatia (CroVID-20) }\end{array}$ & June 2020 & $\begin{array}{l}\text { View } \\
\text { point }\end{array}$ & Earthquake & $\begin{array}{l}\text { Healthcare } \\
\text { system }\end{array}$ \\
\hline 8 & $\begin{array}{l}\text { COVID-19 pandemic and } \\
\text { Zagreb earthquakes as } \\
\text { stressors in patients with } \\
\text { temporomandibular } \\
\text { disorders }\end{array}$ & June 2020 & $\begin{array}{l}\text { Original } \\
\text { research }\end{array}$ & Earthquake & $\begin{array}{l}\text { Physical } \\
\text { health }\end{array}$ \\
\hline 9 & $\begin{array}{l}\text { COVID-19 jeopardizes the } \\
\text { response to coming natural } \\
\text { disasters }\end{array}$ & May 2020 & Editorial & Natural disasters & Health system \\
\hline 10 & $\begin{array}{l}\text { Cascading Risks of COVID-19 } \\
\text { Resurgence During an Active } \\
2020 \text { Atlantic Hurricane } \\
\text { Season }\end{array}$ & $\begin{array}{l}\text { August } \\
2020\end{array}$ & $\begin{array}{l}\text { View } \\
\text { point }\end{array}$ & Hurricane & $\begin{array}{l}\text { Healthcare } \\
\text { system }\end{array}$ \\
\hline 11 & $\begin{array}{l}\text { An Eye on Covid: Hurricane } \\
\text { Preparedness at a COVID-19 } \\
\text { Alternative Care Site }\end{array}$ & $\begin{array}{l}\text { September } \\
2020\end{array}$ & $\begin{array}{l}\text { Case } \\
\text { report }\end{array}$ & Hurricane & $\begin{array}{l}\text { Health system } \\
\text { and facilities }\end{array}$ \\
\hline 12 & $\begin{array}{l}\text { A multi-hazards earth } \\
\text { science perspective on the } \\
\text { COVID-19 pandemic: the }\end{array}$ & May 2020 & $\begin{array}{l}\text { Original } \\
\text { research }\end{array}$ & Earthquake & Health system \\
\hline
\end{tabular}


potential for concurrent and cascading crises

13 The Southwest Monsoon During COVID-19 Pandemic:

July 2020

Editorial

Flood

Health system

A Potential Concern

The subjects of all 13 articles included the coincidence of COVID-19 and natural disaster as well as communities' healthcare systems at the same time. Earthquake, flood, hurricane, tornado and wildfire were the natural disasters which their coincidence with COVID-19 had been investigated. Of these, earthquake was the most frequent disaster which its coincidence with COVID-19 was studied by researchers (31\%). All selected articles were published between April and September 2020. Editorial articles had the highest rate of document type (38.5\%) and policy analysis was published at least (7.7\%). About 10 out of 13 articles (77\%) were investigated the effects of COVID-19 and natural disasters coincidence on healthcare system and had implications for the health system rather than mental or physical health (Table 2).

Table 2) The frequency of hazard type, article type and health effect 


\begin{tabular}{|c|c|c|c|c|}
\hline No & Subjects & & $\mathbf{N}$ & $N(\%)$ \\
\hline \multirow[t]{6}{*}{1} & \multirow[t]{6}{*}{ Hazard type } & Earthquake & 4 & 31 \\
\hline & & Flood & 2 & 15.4 \\
\hline & & Hurricane & 3 & 23 \\
\hline & & Tornado & 1 & 7.6 \\
\hline & & Wildfire & 1 & 7.6 \\
\hline & & All hazard approach & 2 & 15.4 \\
\hline \multirow[t]{5}{*}{2} & \multirow[t]{5}{*}{ Article type } & Editorial & 5 & 38.5 \\
\hline & & Original research & 3 & 23 \\
\hline & & Viewpoint & 2 & 15.4 \\
\hline & & Case report & 2 & 15.4 \\
\hline & & Policy analysis & 1 & 7.7 \\
\hline \multirow[t]{3}{*}{3} & \multirow[t]{3}{*}{ Health section } & Health system & 10 & 77 \\
\hline & & Physical/environmental health & 2 & 15.4 \\
\hline & & Mental health & 1 & 7.6 \\
\hline
\end{tabular}

\section{Implications for health system preparedness and response}

Coincidence of COVID-19 and natural disasters requires a prepared health system for effective response which can prevent more deaths and disabilities. Accordingly, the suggestions, recommendations and implications of public health scholars who have studied the co-occurrence of COVID-19 and natural disasters were considered in three sections of climatic events, earthquakes and all hazard approach.

\section{Climatic events and COVID-19}

Some authors discussed the co-occurrence of climatic events such as flood, hurricane and tornado and COVID-19. For example, the study of southwest monsoon during COVID-19 pandemic concluded that a timely preparedness for monsoon season during ongoing COVID-19 is necessary. Planning mitigations and preparedness of health systems should be done by the participations of health staff, departments of disaster management as well as South Asian countries officials (11). Accordingly, designing and activating the MMS by Louisiana Department of Health to lessen the pressure on hospitals overwhelmed by COVID-19 epidemic can be considered as a suitable implication. Experience on historical exposure to 
hurricanes caused MMS to plan for possible hurricane event as a priority. The plan included preparedness for medical supplies, staffing, incident command, patient care and coordination. Utilizing the patient safety and medical operations continuity as well as meeting the health needs of people affected by the Tropical Strom were the benefits of creating MMS. Establishing such structure can reinforce the emergency operations during an unexpected pandemic of COVID-19 (19).

Similarly, three steps have been suggested to reduce the risk of COVID-19 and hurricane coincidence in the near future. The first step is to establish COVID-19 prevention lifestyle at the time of occurring convergent disasters. Such prevention includes reconsidering physical distancing as well as effective disaster risk reduction strategies. The second step consists of strengthening communication in order to forming safer sheltering and evacuation in the regions affected by co-occurrence of COVID-19 and hurricane. Communication strategies should motivate and encourage people to evacuate and shelter safely, more especially vulnerable populations who may not evacuate at the time of hurricane threats. The COVID-19 prevention guide should be provided for populations living in highly hazard-prone regions. The prepared guidance needs to include such preventive criteria as washing hands, wearing mask, suitable ventilation and surface cleaning. The third step consists of learning from the lessons obtained from the coincidence of COVID-19 and the last storm (2020) to improve the disaster management actions (20). Similarly, the study which investigated flood impacts during COVID-19 epidemic in China, discussed that the effects of floods on physical and mental health of people infected by COVID-19 have not been obvious. The authors suggested urgent measures to prevent health and livelihood consequences of floods at the time of COVID-19 pandemic in China (21).

While addressing COVID-19 pandemic requires resources and supplies, tornado destroyed the pharmacy storage in March 2020. The pharmacy system tried to respond to tornado as a natural disaster and the COVID-19 pandemic. Accordingly, a number of implications has been suggested as lessons learned from the pharmacy system measures during the coincidence of COVID-19 and natural disasters. External and multidisciplinary collaborations, effective communication among departments and teamwork were the most important implications learned from the authors' experiences. Since tornado affected supply storage, medications and health delivery system, a strong disaster response system as well as effective collaborations and communications facilitated responding to COVID-19 epidemic (22).

In the similar article, the authors discussed two scenarios regarding the dual risk of COVID-19 pandemic and hurricane. Firstly, higher rates of hurricane related injuries and deaths among people who declined to evacuate due to being afraid of COVID-19 and secondly, increase of COVID-19 cases due to sheltering the evacuees. The authors suggested that sheltering or evacuating along with protective actions for limiting the spread of COVID-19 can be much safer for the highly hurricane prone communities. Such precaution actions included physical distancing, use of mask, hand washing and mass gatherings avoidance. Considering and following the public health surveillance steps such as case identification, isolation, quarantine, and contact tracing can be crucial as well. To control COVID-19 pandemic, the anti-contagion policies and strategies as well as hygiene interventions were chosen by public health managers and healthcare providers in the absence of COVID-19 vaccine. The health system needs to balance the 
reduction of COVID-19 transmission possibility and minimize the risk of hurricane exposure. Releasing guidance and protocols on sheltering during COVID-19 pandemic can be helpful. In addition, a 14-days self-quarantine of people who used mass shelters at the time of hurricanes, control of infections in shelter settings, checking symptom frequently, prepackaged meal and disinfection of surfaces as well as staying in assigned places can be considered at the time of sheltering. Finally, educating evacuation and sheltering behaviors to people during COVID-19 and applying lessons learnt from the previous hurricanes were suggested by the authors (23).

Healthcare providers should be prepared for wildfire season in order to protect patients and vulnerable people from smoke. There has been a number of conflicts during the coincidence of COVID-19 pandemic and wildfire events. For example, in-home sheltering and applying portable air cleaners may be more emphasized due to physical distancing guideline in wildfire seasons during COVID-19 pandemic. Furthermore, although surgical mask and cloth can help decrease COVID-19 transmission, they provide limited protection from wildfire smoke. Accordingly, balancing the actions for responding to the dual risks of COVID-19 and wildfire events can be vital. For instance, in addition to personal protective operations, healthcare facilities should be supplied and assessed by ventilation, heating and air conditioning experts to be prepared for the COVID-19 pandemic in the summer months. The preparedness for wildfire smoke requires the collaborative actions of public and environmental health experts as well (24).

\section{Earthquakes and COVID-19}

Balancing the risks of COVID-19 and disaster response and recovery actions has been considered in the evidence which studied the co-occurrence of COVID-19 and earthquake. In addition, including natural disaster inputs into COVID-19 epidemiological modeling has been suggested as an effective action which can improve the disaster preparedness and planning for COVID-19 mitigation strategies in the future. Furthermore, sharing scientific information such as models with developing countries has been recommended due to their lack of capacity to generate resilience-related knowledge. In addition, planning for equipping the poor and developing countries and regions in order to preparation and response to natural disasters at the time of COVID-19 pandemic can help decrease the consequences of disasters. The evacuation centers should be available with the social distancing capacity as well as the availability of personal protective equipment and medical supplies such as respirators in regions affected by COVID19. Other implications included strengthening disaster coordination to inform COVID-19 epidemic response; identifying economic implication for COVID-19; improving community-based response and preparedness for coincidence of COVID-19 and disasters; preparing recovery plan at early phase. Finally, building resilience and disaster risk governance can reduce the risk of natural disasters during the pandemic such as COVID-19 (25).

The risk of increasing the cases of COVID-19 in combination with a natural disaster such as earthquakes is higher. The experiences of Croatia earthquake at the time of COVID-19 showed that a well-established health system as well as coordinated collaborations during outbreak response helped healthcare managers mitigate possible effects (26). On the other hand, the coincidence of COVID-19 and 
earthquakes played as a stressor for a number of illness such as patients with TMD disorders. However, a related study revealed that COVID-19 were more stressful than earthquakes for TMD patients who lived in earthquake affected regions. Relevant evaluation can identify the psychological information of patients. Such evaluation can help understand the pain and disability problems of patients who were affected by co-occurrence of COVID-19 and natural disasters (27). In addition, COVID-19 pandemic which is reinforced by disastrous events affected people's mental health remarkably. The level of people susceptibility to mental health effects of pandemic and earthquakes co-occurrence is related to individual's resiliency or resistance. In addition, pre and post-disaster context as well as people's characteristics can influence the mental health interventions. The required care should be provided by resources allocated to mental health system activation in the regions affected by both natural disasters and COVID-19 pandemic (28).

\section{All hazard approach}

The plans which need to be made regarding the coincidence of COVID-19 and natural disasters have been classified into two parts of contingency planning; and pre-crisis planning and coordination. Reducing the health impacts of natural disasters at the time of COVID-19 transmission needs contingency plan with the aim of improving disaster health management affairs. Contingency planning includes protocols for safe work, social distancing actions and analysis of worst-case scenarios based on the results of risk assessment. On the other hand, pre-disaster planning focuses coordination of stakeholders as well as optimizing resources in order to responding to potential effects of COVID-19 and upcoming natural disasters coincidence. The increase of international cooperation as well as improving disaster health management systems can help countries, especially developing ones, encounter dual risk of COVID-19 pandemic and natural disasters (10). In addition, the cascading effects of natural disaster, COVID-19 pandemic and complex emergencies are not well known. Responding to such multi-hazard situation should be considered in risk legislation and planning during disaster prevention and preparedness phases. Furthermore, additional financial resources allocation for doing research in regions affected by multi-hazard risk of natural disaster and COVID-19 pandemic can help decrease their unsafe future as well as strengthening community resiliency through policy-making and planning (7).

\section{Conclusion}

While there is a little known about the co-occurrence of COVID-19 and a natural disaster, our findings may help governments to establish risk reduction plans and strategies for cascading natural disasters during COVID-19 pandemic. In addition, extracting the lessons learned from the regions affected by disasters at the time of COVID-19 pandemic can be helpful for healthcare professionals and policy-makers to modify their preparedness and response plans for cascading risk of natural disasters and a serious pandemic such as COVID-19. Further research is needed to identify the factors strengthen the preparedness of health system for the dual risk of natural hazards and pandemics. Furthermore, conducting community- 
based research projects in the regions affected by coincidence of natural disasters and COVID-19 can provide the healthcare administrators useful information for planning and decision-making.

\section{Abbreviations}

MMS: Medical Monitoring Station

TMD: Temporomandibular

\section{Declarations}

\section{Ethics approval and consent to participate}

This study was approved by the ethics committee of Shahid Beheshti Universityof Medical Sciences, Tehran, Iran (IR.SBMU.PHNS.REC.1399.052). The consent to participate is not applicable for this review.

\section{Consent for publication}

Not applicable

\section{Availability of data and materials}

The datasets used and/or analysed during the current study are available from the corresponding author on reasonable request.

\section{Competing interests}

The authors declare that they have no competing interests.

\section{Funding}

This study was funded by Shahid Beheshti University of Medical Sciences, Tehran, Iran. The funder was not involved in the design of the study or the collection, analysis, and interpretation of data, or in writing the manuscript

\section{Authors' contributions}

SS designed, analyzed and interpreted the data extracted from the articles and was a major contributor in drafting the manuscript. SHY contributed in data collection and writing the paper. AHB contributed in the design of the study and data collection. MHV contributed in data analysis and writing article. All authors read and approved the final manuscript

\section{Acknowledgements}


We would like to appreciate some collaborative researchers who improve our study through their review and scientific comments during the research process.

\section{References}

1. Watson JT, Gayer M, Connolly MA. Epidemics after natural disasters. Emerging infectious diseases. 2007;13(1):1.

2. Kouadio IK, Aljunid S, Kamigaki T, Hammad K, Oshitani H. Infectious diseases following natural disasters: prevention and control measures. Expert Rev Anti-Infect Ther. 2012;10(1):95-104.

3. Lippi G, Favaloro EJ, Plebani M. Laboratory medicine and natural disasters: are we ready for the challenge? Clinical chemistry and laboratory medicine. 2010;48(5):573-5.

4. Chen J. Pathogenicity and transmissibility of 2019-nCoV-a quick overview and comparison with other emerging viruses. Microbes and infection. 2020; 22(2);69-71.

5. Munster VJ, Koopmans M, van Doremalen N, van Riel D, de Wit E. A novel coronavirus emerging in China-key questions for impact assessment. New England Journal of Medicine. 2020;382(8):692-4.

6. Shi W, Hall BJ. What can we do for people exposed to multiple traumatic events during the coronavirus pandemic? Asian J Psychiatry. 2020; 51: 102065. doi: 10.1016/j.ajp.2020.102065

7. Hariri-Ardebili MA. Living in a multi-risk chaotic condition: Pandemic, natural hazards and complex emergencies. Int J Environ Res Public Health. 2020;17(16):1-16.

8. Report on 2020 Nowrouz floods in Iran. ISNA. 2020 Available from: https://www.isna.ir/. Accessed October 2020.

9. Report on 2020 Tehran Earthquake. ISNA database. 2020 Available from: from https://www.isna.ir/news. Accessed October 2020

10. Cardil A, de-Miguel S. COVID-19 jeopardizes the response to coming natural disasters. Saf Sci. 2020;130:104861.

11. Vikas. The Southwest Monsoon During COVID-19 Pandemic: A Potential Concern. Asia-Pac J Public Health. 2020; 32(6-7): 374-375.

12. Harrison CG, Williams PR. A systems approach to natural disaster resilience. Simulation Modelling Practice and Theory. 2016;65:11-31.

13. Simonovic SP. Systems approach to management of disasters: methods and applications: John Wiley \& Sons; 2010.

14. Izumikawa K. Infection control after and during natural disaster. Acute Medicine \& Surgery. 2019;6(1):5-11.

15. Songsore J. The complex interplay between everyday risks and disaster risks: the case of the 2014 cholera pandemic and 2015 flood disaster in Accra, Ghana. Int J Disaster Risk Reduct. 2017;26:4350 .

16. Jafari N, Shahsanai A, Memarzadeh M, Loghmani A. Prevention of communicable diseases after disaster: A review. Journal of research in medical sciences: the official journal of Isfahan University 
of Medical Sciences. 2011;16(7):956.

17. Fearnley CJ, Dixon D. Early Warning Systems for Pandemics: Lessons Learned from Natural Hazards. Int J Disaster Risk Reduct. 2020; 49: 101674. 10.1016/j.ijdrr.2020.101674

18. World Health Organization. Novel Coronavirus (2019-nCoV): Strategic Preparedness and Response Plan. 2020. Available from https://www.who.int/publications/i/item/strategic-preparedness-andresponse-plan-for-the-new-coronavirus. Accessed September 2020.

19. Maslanka M, Hurwitz JA. An Eye on COVID: Hurricane Preparedness at a COVID-19 Alternative Care Site. Disaster Med Public Health Preparedness. 2020:1-7.

20. Shultz JM, Fugate C, Galea S. Cascading risks of COVID-19 resurgence during an active 2020 Atlantic hurricane season. Jama. 2020;324(10):935-6.

21. Guo Y, Wu Y, Wen B, Huang W, Ju K, Gao Y, et al. Floods in China, COVID-19, and climate change. The Lancet Planetary Health. 2020;4(10):e443-e4.

22. Zuckerman AD, Patel PC, Sullivan M, Potts A, Knostman M, Humphreys E, et al. From natural disaster to pandemic: A health-system pharmacy rises to the challenge. American Journal of Health-System Pharmacy. 2020.

23. Shultz JM, Kossin JP, Hertelendy A, Burkle F, Fugate C, Sherman R, et al. Mitigating the twin threats of climate-driven Atlantic hurricanes and COVID-19 transmission. Disaster Med Public Health Preparedness. 2020:1-10.

24. Henderson SB. The CoViD-19 pandemic and wildfire smoke: Potentially concomitant disasters. American Public Health Association; 2020.

25. Quigley MC, Attanayake J, King A, Prideaux F. A multi-hazards earth science perspective on the COVID-19 pandemic: the potential for concurrent and cascading crises. Environment Systems \& Decisions. 2019:1.

26. Rok Č, Alemka M, Krunoslav C. Earthquake in the time of COVID-19: The story from Croatia (CroVID20). J Glob Health. 2020;10(1).

27. Vrbanović E, Alajbeg IZ, Alajbeg I. COVID-19 pandemic and Zagreb earthquakes as stressors in patients with temporomandibular disorders. Oral Diseases. 2020;00:1-6.

28. Marko C, Andro K, Petrana B. Stay home while going out-possible impacts of earthquake cooccurring with COVID-19 pandemic on mental health and vice versa. Brain Behav Immun. 2020; 87: 82-83.

\section{Figures}



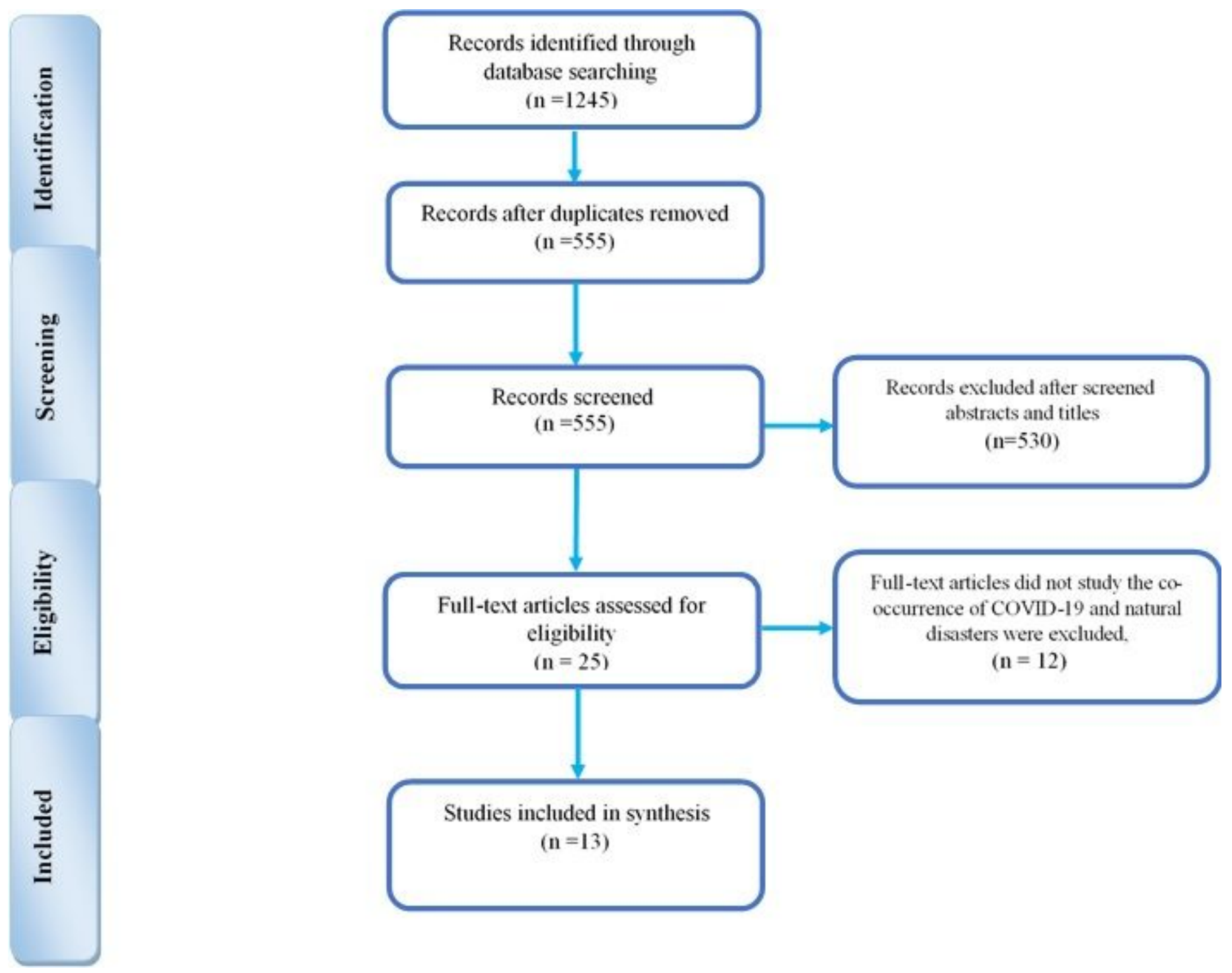

Figure 1

Article screening based on the PRISMA digram 